\title{
The ins and outs of German unemployment: a transatlantic perspective
}

\author{
By Matthias S. Hertweck ${ }^{a}$ and Oliver Sigrist ${ }^{b}$ \\ aUniversity of Konstanz, Department of Economics, Box 145, 78457 Konstanz, Germany; \\ e-mail: matthias.hertweck@uni-konstanz.de \\ ${ }^{b}$ University of Basel and Swiss National Bank, P.O. Box, 8022 Zurich, Switzerland; \\ e-mail: oliver.sigrist@snb.ch
}

\begin{abstract}
This article decomposes fluctuations in the German unemployment rate into changes in inflows (job separation) and outflows (job finding). For this purpose, we construct and examine monthly labour market transition rates from the West German sample of the SOEP (and the CPS) for the period 1984-2009. We explicitly take account of the low level of labour market transition rates in Germany. Our article shows that in West Germany, changes in the inflow rate are more important (about $60 \%$ ) than changes in the outflow rate, whereas in the USA close to $80 \%$ are due to changes in the outflow rate.
\end{abstract}

JEL classifications: E24, E32, J63, J64

\section{Introduction}

The German social-market economy has seen good and bad times in the post-war era. After a series of negative shocks in the 1970s and the early 1980s, the German unemployment rate surged to unprecedented levels—as in the USA and many other countries. However, during the late 1980s and 1990s, the US unemployment rate returned to normal levels, whilst the German unemployment rate continued to rise. At the peak of its crisis, when more than four million unemployed were registered with the Federal Employment Agency, Germany was considered the 'sick man of Europe' (The Economist, 1999). More recently, the German labour market has recovered vigorously. In particular, the unemployment rate continued to fall during the Great Recession-even though Germany experienced an even sharper decline in GDP per capita than the USA (Burda and Hunt, 2011). This extremely favourable performance-sometimes referred to as the German labour market 'miracle' (Möller, 2010)-has sparked renewed interest in the dynamics of the German labour market (see, e.g., Sala et al., 2013).

The starting point of our analysis is the unemployment accounting identity (Darby et al., 1986). Unemployment fluctuations are driven by changes in two different 
channels-unemployment inflows (job separation) and unemployment outflows (job finding). For this purpose, we construct gross worker flows from the West German sample of the Socio-Economic Panel (SOEP, 2011), a household survey representative of the entire population of Germany. We thereby ensure best comparability with evidence from the Current Population Survey (CPS, 2012) for the USA. Our final sample consists of monthly labour market transition rates from both countries for the period 1984M7-2009M6.

We find that even though the average unemployment rate is close to $5.5 \%$ in both samples, the level of the underlying labour market transition rates is very different. Both the unemployment inflow and the unemployment outflow rate in West Germany are lower by an order of magnitude. In terms of cyclicality, most of the recent literature argues that changes in the US unemployment rate are mainly caused by movements in the outflow rate. ${ }^{1}$ Importantly, however, the standard approach to decomposing the 'ins and outs' of unemployment (Fujita and Ramey, 2009) presumes that the actual unemployment rate is sufficiently well approximated by the corresponding steady-state unemployment rate. As pointed out by Elsby et al. (2013), this requires that the underlying transition rates are sufficiently high. In the USA this condition seems satisfied, though certainly not in West Germany. For this reason, we estimate the ins and outs of West German unemployment using the non-steady-state decomposition method developed by Smith (2011) and Elsby et al. (2013). This method imposes much less restrictive assumptions and nests the steadystate approach as a special case. Our main result is that in West Germany, close to $60 \%$ of changes in the actual unemployment rate are due to changes in the unemployment inflow rate-compared with only $20 \%$ in the USA.

In contrast to our work, both previous studies that have investigated the ins and outs of German unemployment (Jung and Kuhn, 2014; Nordmeier, 2014) are based on gross worker flows from the IAB employment panel. These data are very accurate, but cover only social security employment and those unemployed who receive benefits (Bachmann and Schaffner, 2009). All other individuals (civil servants, self-employed persons, unemployed not entitled to benefits, and inactive individuals out of the labour force) are observationally equivalent ('information gap'). Nordmeier (2014) addresses this issue by using the nonemployment proxy developed by Fitzenberger and Wilke (2010). Based on a non-steadystate decomposition, Nordmeier (2014) argues that the outflow rate accounts for more variation in the non-employment proxy than the inflow rate. As SOEP data capture inactivity (non-participation) explicitly, we are also able to decompose changes in the nonemployment rate. Interestingly, our results are quantitatively very similar to hers. We can thus reconcile apparent contradictions in the results. Alternatively, Jung and Kuhn (2014) treat all information gaps between labour market entry and retirement as inactivity. Consequently, their estimated contribution of indirect transitions involving inactivity is more than $50 \%$ larger than in our sample. Yet consistent with our results, they find that the unemployment inflow rate in West Germany is more important (about 60\%) than the unemployment outflow rate. The similarity to our result is reassuring but by no means selfevident. In particular, we find that the steady-state decomposition method predicts the same dominating margin as the non-steady-state decomposition method in only six out of

1 The estimates range from 60\% (Fujita and Ramey, 2009) to 80\% (Shimer, 2012). However, as emphasized by Yashiv (2008), Elsby et al. (2009), and Fujita (2011), this does not mean that changes in the inflow rate are not relevant. Instead, changes in the inflow rate seem to play an important role at the beginning of recessions (see also the discussion of Davis, 2006, on Hall, 2006, on this aspect). 
nine West German sub-samples. This implies that the application of the steady-state decomposition method to countries with low labour market transition rates is not innocuous.

The remainder of this article is organised as follows. Section 2 documents the construction of gross worker flows based on SOEP and CPS data. Section 3 describes the nonsteady-state decomposition method. Section 4 presents the results. Section 5 discusses the results in light of the recent literature. Section 6 concludes.

\section{Data and measurement}

We estimate monthly gross worker flows between the labour force states of employment, $E$, unemployment, $U$, and inactivity, $I$, using the West German sample of the SOEP. Online Appendix Figure A.1 shows that the SOEP unemployment rate behaves very similarly to the West German unemployment rate according to the ILO definition. We thus ensure best comparability with evidence from the (ILO-compatible) CPS for the USA. This is advantageous, as the USA serves as a well-understood benchmark case (Yashiv, 2008; Elsby et al., 2009; Fujita and Ramey, 2009; Fujita, 2011; Shimer, 2012) of a flexible labour market with stable institutions. We therefore offer cross-country comparisons throughout this article.

\subsection{Definition of direct and indirect transition rates}

To measure gross worker flows, we consider a three-state model where individuals are either employed, $E$, unemployed, $U$, or inactive, I. In continuous time, these three states evolve according to the following system of equations: ${ }^{2}$

$$
\begin{gathered}
\dot{U}_{t}=\lambda_{t}^{E U} E_{t}+\lambda_{t}^{I U} I_{t}-\left(\lambda_{t}^{U E}+\lambda_{t}^{U I}\right) U_{t} \\
\dot{E}_{t}=\lambda_{t}^{U E} U_{t}+\lambda_{t}^{I E} I_{t}-\left(\lambda_{t}^{E U}+\lambda_{t}^{E I}\right) E_{t} \\
\dot{I}_{t}=\lambda_{t}^{U I} U_{t}+\lambda_{t}^{E I} E_{t}-\left(\lambda_{t}^{I U}+\lambda_{t}^{I E}\right) I_{t}
\end{gathered}
$$

where, following Shimer (2012), $\lambda_{t}^{X Y}$ denotes the Poisson transition rate from labour force state $X$ to labour force state $Y$ at time $t$; that is, $\lambda_{t}^{X Y}=-\ln \left(1-\left(X Y_{t} / X_{t-1}\right)\right)$. In the steadystate, when all three labour force states are constant; that is, $\dot{U}_{t}=\dot{E}_{t}=\dot{I}_{t}=0$, we can express the steady-state unemployment rate, $u_{t}^{*}$, as:

$$
u_{t}^{*}=\frac{s_{t}}{s_{t}+f_{t}}=\frac{\left(\lambda_{t}^{E U}+\lambda_{t}^{E I} \frac{\lambda_{t}^{I U}}{\lambda_{t}^{I U}+\lambda_{t}^{I E}}\right)}{\left(\lambda_{t}^{E U}+\lambda_{t}^{E I} \frac{\lambda_{t}^{I U}}{\lambda_{t}^{I U}+\lambda_{t}^{I E}}\right)+\left(\lambda_{t}^{U E}+\lambda_{t}^{U I} \frac{\lambda_{t}^{I E}}{\lambda_{t}^{I U}+\lambda_{t}^{I E}}\right)}
$$

where the total inflow rate, $s_{t}$, is defined as the sum of the direct transition rate from employment to unemployment, $\lambda_{t}^{E U}$, plus the indirect transition rate, $\lambda_{t}^{E I U}$. The latter is given by the product of the transition rate from employment to inactivity, $\lambda_{t}^{E I}$, times the share of inactivity exits to unemployment. The total outflow rate, $f_{t}$, is defined accordingly.

\subsection{West German data}

The SOEP (2011) is an annual survey of households representative of the entire population of Germany. Launched in 1984, it constitutes the longest-running household survey in

2 The current subsection largely follows Smith (2011), who summarises the strategy of Shimer (2012). 
Europe, spanning more than three complete business cycles (Haile, 2009). The West German sample covers on average 10,134 individuals aged 16-65. Individual weights are adjusted to the marginal distributions of age, gender, and nationality. Moreover, the SOEP attempts to track all individuals interviewed in the preceding wave. Ignoring deaths and moves abroad, more than $25 \%$ of first-wave respondents are still being interviewed after 27 years in $2010 .^{3}$

The SOEP (2011) covers historical calendar data from 1983 to 2009 (which was collected from 1984 to 2010). At the annual interview, individuals are asked to fill in a detailed questionnaire on their current socio-economic situation and a calendar form that collects their historical labour force status for each month of the preceding year. We use the overlapping information of two consecutive years to control for systematic recall error (Wolff, 1998, Chapter 2; Jürges, 2007). Thus, all calendar data from 1983 or the entire first year of appearance of an individual are used for reconciliation purposes only, but ignored in the following analysis. In total, our reconciliation procedure reduces the average number of individuals from 10,134 to 9,044 in a typical month. The exact reconciliation procedure is described in Online Appendix Section A.2.2. ${ }^{4}$ Second, as in Fujita et al. (2007) or Smith (2011), we take 12-month centred moving averages ${ }^{5}$ to remove high-frequency movements including seasonal variations. Third, based on Fujita and Ramey (2009), we adjust for margin error (see Online Appendix Section A.2.4). Fourth, following Shimer (2012), we correct for time aggregation bias in the data (see Online Appendix Section A.2.5). The left panel of Online Appendix Figure A.3 illustrates that our data treatment procedure affects mainly the level of the labour market transition rates, rather than their cyclical behaviour. Our final sample covers the period 1984M7-2009M6.

We study the properties of the full sample representative of the entire population of West Germany, the 'foreigner' sample, ${ }^{6}$ the 'German' sample, and the 'German' sample disaggregated by gender, age (young, prime age, and old), and educational background (low-skilled and high-skilled). We define the set of prime-age individuals using the observation that the West German labour force participation rate is extremely stable between the ages 29 and 49; that is, the change from one birth cohort to the next is below 1 percentage point (see Online Appendix Figure A.4). High-skilled individuals are required to hold at least a school-leaving qualification sufficient for admission to a university of applied sciences (Fachhochschulreife).

\subsection{US data}

Launched in 1948, the CPS (2012) is the major source of US labour market statistics, including the official measures of unemployment and labour force participation. We match

3 For these and further details, see the data documentation of Kroh (2011).

4 Figure A.2 in the Online Appendix shows that the reconciled UE transition rate does not exhibit a peak at an unemployment duration of 12 months (as in Biewen and Wilke, 2005). This indicates that our procedure successfully eliminates a large portion of spurious transitions at the beginning/end of the calendar year (so-called seam bias or heaping, see Kraus and Steiner, 1998; Wolff and Augustin, 2003).

5 To be precise, the 12-month centred moving average is based on the past 6 months, the current month, and the following 5 months.

6 Note that the foreigner sample covers households with a household head from one of the five traditional immigrant nationalities in West Germany (Greek, Italian, Spanish, Turkish, and former Yugoslavian). The German sample covers all other households. 
individual records across periods using the code of Shimer (2012). Due to panel rotation, at most $75 \%$ of all individuals can be matched from one month to the next. In practice, however, the share of matched records is considerably lower (Abowd and Zellner, 1985). As no attempt is made to follow up individuals who change residence (Fujita et al., 2007), we note that panel attrition in the CPS is more severe than in SOEP data. On average, the CPS (2012) covers 67,045 individuals aged 16-65 in our sample.

Both reconciled West German data and US data are treated equally. In particular, we take 12-month centred moving averages to remove high-frequency movements including seasonal variations, we adjust for margin error, and we correct for time aggregation bias. Online Appendix Figure A.3 shows that in contrast to West Germany, the (dampening) impact of the margin error correction procedure seems quantitatively less important than the (elevating) effect of time aggregation adjustment. To define the sample of prime-age workers (here: all cohorts between 25 and 49 years), we apply the same criterion as for SOEP data; that is, the change in the labour force participation rate must be below 1 percentage point from one birth cohort to the next (see Online Appendix Figure A.4). High-skilled individuals are required to have completed at least 'some college'.

\subsection{Comparative descriptive statistics}

Tables 1 and 2 summarise the descriptive statistics for West Germany and the USA. For the period $1984 \mathrm{M} 7-2009 \mathrm{M} 6$, the average unemployment rate is close to $5.5 \%$ in both countries. The level of both labour market transition rates in West Germany, however, is lower by about an order of magnitude (see also Schmidt, 2000; Bachmann, 2005; Gartner et al., 2012). Indirect transitions via inactivity constitute about 18\% (women: $22 \%$ ) of all transitions in West Germany and even more than 28\% (women: 32\%) in the USA. Young adult unemployment seems to be a more serious problem in the USA $(U=11.6 \%)$ than in West Germany $(U=5.0 \%)$, whilst the older unemployed in West Germany have a very hard time finding a job $(F=3.0 \%)$. In both countries, the level of education seems to be a very important determinant of the sample-specific unemployment rate. In West Germany, the unemployment rate in the high-skilled sub-sample $(U=2.5 \%)$ is lower than in the low-skilled sub-sample $(U=5.9 \%)$, since high-skilled individuals find new jobs much faster $(F=13.8 \%)$ than do low-skilled individuals $(F=5.2 \%)$. In the USA, on the other hand, the unemployment rate in the high-skilled sub-sample $(U=2.8 \%)$ is lower than in the lowskilled sub-sample $(U=7.1 \%)$, since the risk of job loss is substantially higher for lowskilled individuals $(S=3.7 \%)$ than for high-skilled individuals $(S=1.6 \%)$.

Figure 1 illustrates the total inflow rate, the total outflow rate, and the sample-specific unemployment rate for both countries. From 1990 to 2005, the West German unemployment rate displays a protracted rise, which was only shortly interrupted between 1997-2000. Since 2005, we note a gradual but steady decline. Importantly, the unemployment rate continued to fall even during the Great Recession-even though Germany experienced an even sharper decline in GDP per capita than did the USA (Burda and Hunt, 2011). Over the full sample period, the unemployment rate co-moves positively with the total inflow rate and negatively with the total outflow rate, where-at first glance-the cyclical comovement with the total inflow rate seems stronger. We also note that both transition rates are subject to substantial high-frequency variations.

Surprisingly, the pattern observed in the USA is very different. After a long-lasting downwards trend that started in the mid-1980s, the US unemployment rate reached a bottom at 
Table 1. Descriptive statistics: first moments

\begin{tabular}{|c|c|c|c|c|c|c|c|c|c|c|}
\hline & $\begin{array}{l}\text { Full } \\
\text { sample }\end{array}$ & $\begin{array}{l}\text { German } \\
\text { sample }\end{array}$ & Foreigners & Males & Females & Young & $\begin{array}{l}\text { Prime- } \\
\text { age }\end{array}$ & Old & $\begin{array}{l}\text { Low- } \\
\text { skilled }\end{array}$ & $\begin{array}{l}\text { High- } \\
\text { skilled }\end{array}$ \\
\hline \multicolumn{11}{|c|}{ Panel A: West Germany } \\
\hline$N$ & 9,044 & 7,577 & 1,467 & 3,720 & 3,857 & 1,599 & 3,808 & 2,169 & 4,816 & 2,756 \\
\hline$U$ & $5.3 \%$ & $4.6 \%$ & $12.1 \%$ & $4.1 \%$ & $5.4 \%$ & $5.0 \%$ & $3.4 \%$ & $7.0 \%$ & $5.9 \%$ & $2.5 \%$ \\
\hline$S$ & $0.3 \%$ & $0.3 \%$ & $0.4 \%$ & $0.3 \%$ & $0.3 \%$ & $0.5 \%$ & $0.3 \%$ & $0.3 \%$ & $0.3 \%$ & $0.3 \%$ \\
\hline$F$ & $6.2 \%$ & $7.1 \%$ & $2.7 \%$ & $7.4 \%$ & $6.6 \%$ & $10.2 \%$ & $8.5 \%$ & $3.0 \%$ & $5.2 \%$ & $13.8 \%$ \\
\hline$E U$ & $0.3 \%$ & $0.3 \%$ & $0.3 \%$ & $0.3 \%$ & $0.2 \%$ & $0.4 \%$ & $0.2 \%$ & $0.2 \%$ & $0.3 \%$ & $0.3 \%$ \\
\hline EIU & $0.1 \%$ & $0.1 \%$ & $0.1 \%$ & $0.0 \%$ & $0.1 \%$ & $0.1 \%$ & $0.0 \%$ & $0.0 \%$ & $0.0 \%$ & $0.0 \%$ \\
\hline$U E$ & $5.1 \%$ & $5.9 \%$ & $1.8 \%$ & $6.7 \%$ & $5.2 \%$ & $8.6 \%$ & $7.8 \%$ & $2.7 \%$ & $4.0 \%$ & $11.1 \%$ \\
\hline UIE & $1.1 \%$ & $1.1 \%$ & $0.9 \%$ & $0.7 \%$ & $1.4 \%$ & $1.6 \%$ & $0.8 \%$ & $0.3 \%$ & $1.2 \%$ & $2.8 \%$ \\
\hline \multicolumn{11}{|c|}{ Panel B: USA } \\
\hline$N$ & 67,045 & & & 32,286 & 34,759 & 12,669 & 37,598 & 16,045 & 46,582 & 20,429 \\
\hline$U$ & $5.6 \%$ & & & $5.7 \%$ & $5.5 \%$ & $11.6 \%$ & $4.7 \%$ & $3.6 \%$ & $7.1 \%$ & $2.8 \%$ \\
\hline$S$ & $3.0 \%$ & & & $3.1 \%$ & $2.9 \%$ & $7.6 \%$ & $2.3 \%$ & $1.8 \%$ & $3.7 \%$ & $1.6 \%$ \\
\hline$F$ & $60.5 \%$ & & & $60.5 \%$ & $57.8 \%$ & $66.2 \%$ & $54.6 \%$ & $57.3 \%$ & $56.1 \%$ & $66.6 \%$ \\
\hline$E U$ & $2.0 \%$ & & & $2.3 \%$ & $1.7 \%$ & $4.2 \%$ & $1.7 \%$ & $1.2 \%$ & $2.6 \%$ & $1.2 \%$ \\
\hline$E I U$ & $0.9 \%$ & & & $0.8 \%$ & $1.1 \%$ & $3.4 \%$ & $0.6 \%$ & $0.6 \%$ & $1.1 \%$ & $0.3 \%$ \\
\hline$U E$ & $43.2 \%$ & & & $47.2 \%$ & $39.4 \%$ & $49.8 \%$ & $39.6 \%$ & $37.1 \%$ & $41.1 \%$ & $59.7 \%$ \\
\hline UIE & $17.3 \%$ & & & $13.4 \%$ & $18.5 \%$ & $16.4 \%$ & $14.9 \%$ & $20.2 \%$ & $15.0 \%$ & $6.9 \%$ \\
\hline
\end{tabular}

Notes: The table shows the means of the unemployment rate and the corresponding transition rates for West Germany and the USA.

Table 2. Descriptive statistics: second moments

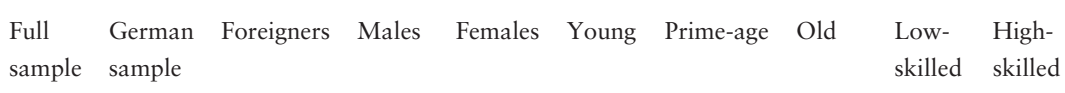

Panel A: West Germany

$\begin{array}{lllllllllll}\sigma(U) & 8.6 \% & 9.1 \% & 8.6 \% & 9.1 \% & 11.0 \% & 11.0 \% & 11.6 \% & 8.8 \% & 9.1 \% & 14.0 \% \\ \sigma(S) & 11.8 \% & 12.3 \% & 20.1 \% & 11.4 \% & 17.5 \% & 11.7 \% & 13.6 \% & 20.9 \% & 14.1 \% & 16.1 \% \\ \sigma(F) & 8.3 \% & 8.3 \% & 20.9 \% & 11.4 \% & 10.5 \% & 12.5 \% & 12.3 \% & 20.4 \% & 10.9 \% & 12.4 \% \\ \sigma(E U) & 11.3 \% & 11.3 \% & 22.3 \% & 11.4 \% & 17.8 \% & 12.2 \% & 13.5 \% & 20.2 \% & 13.5 \% & 17.1 \% \\ \sigma(E I U) & 21.2 \% & 24.5 \% & 58.0 \% & 26.1 \% & 25.9 \% & 37.7 \% & 31.9 \% & 62.0 \% & 32.3 \% & 30.7 \% \\ \sigma(U E) & 9.6 \% & 9.6 \% & 23.0 \% & 13.0 \% & 12.7 \% & 13.7 \% & 14.6 \% & 22.6 \% & 12.7 \% & 13.1 \% \\ \sigma(U I E) & 17.2 \% & 17.4 \% & 43.3 \% & 27.3 \% & 25.5 \% & 33.7 \% & 28.6 \% & 28.3 \% & 19.9 \% & 34.3 \% \\ \text { Panel B: USA } & & & & & & & & & \\ \sigma(U) & 9.9 \% & & & 11.3 \% & 8.3 \% & 7.2 \% & 11.3 \% & 12.1 \% & 9.3 \% & 12.3 \% \\ \sigma(S) & 2.8 \% & & & 4.1 \% & 2.4 \% & 2.3 \% & 3.9 \% & 4.8 \% & 2.6 \% & 4.5 \% \\ \sigma(F) & 10.2 \% & & & 10.8 \% & 9.7 \% & 8.9 \% & 10.6 \% & 12.1 \% & 10.0 \% & 12.3 \% \\ \sigma(E U) & 3.5 \% & & & 4.9 \% & 3.0 \% & 3.0 \% & 4.6 \% & 5.5 \% & 3.6 \% & 4.8 \% \\ \sigma(E I U) & 2.3 \% & & & 3.1 \% & 2.8 \% & 3.8 \% & 2.6 \% & 5.2 \% & 2.4 \% & 5.4 \% \\ \sigma(U E) & 10.7 \% & & & 11.0 \% & 10.5 \% & 9.8 \% & 10.6 \% & 12.7 \% & 10.3 \% & 12.6 \% \\ \sigma(U I E) & 9.3 \% & & & 10.6 \% & 8.6 \% & 7.8 \% & 11.1 \% & 11.6 \% & 9.8 \% & 11.3 \%\end{array}$

Notes: The table shows the standard deviations of the cyclical components of the unemployment rate and the corresponding transition rates for West Germany and the USA. To facilitate comparison with the literature, all time series are time-aggregated to a quarterly frequency, logged, and de-trended using the Hodrick and Prescott (1997) filter with $\lambda=1,600$. 

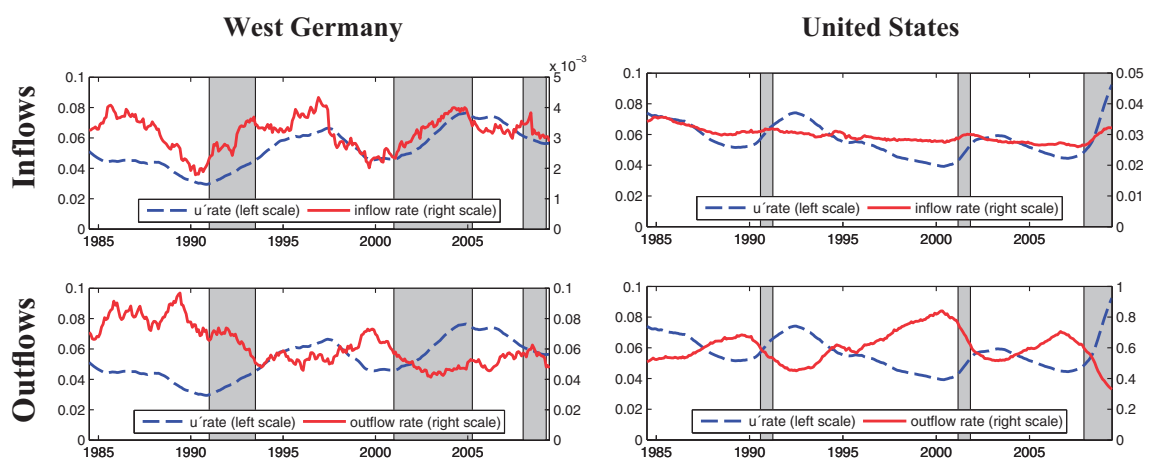

Fig. 1. Unemployment rate (dashed line) contrasted with the total inflow rate (solid line, top panel) and the total outflow rate (solid line, bottom panel), respectively

The grey shaded areas denote recessions dated by the Sachverständigenrat zur Begutachtung der gesamtwirtschaftlichen Entwicklung (2009, p. 260) and the NBER (2010), respectively.

the beginning of the new millennium. Between 2000 and 2007, the US unemployment rate remained at a low level. After the outbreak of the Great Recession, however, we observe a steep increase. In contrast to West Germany, the cyclical co-movement between the unemployment rate and the total outflow rate seems stronger than the cyclical co-movement with the total inflow rate. We also note that both transition rates exhibit much weaker high-frequency movements than in West Germany. This observation is very likely due to the fact that the average number of individuals in the CPS is larger by factor eight (see Table 1).

\section{Non-steady-state decomposition method}

We now present the non-steady-state decomposition method developed by Smith (2011) and Elsby et al. (2013). This method explicitly takes account of the low level of labour market transition rates in West Germany. In addition, it nests the steady-state approach pioneered by Fujita and Ramey (2009)—which serves as a starting point in the following section-as a special case.

\subsection{Steady-state decomposition}

3.1.1 Contributions of contemporaneous transition rates As demonstrated by Fujita and Ramey (2009) and Smith (2011), eq.(4) can be used to decompose changes in the steadystate unemployment rate, $\Delta u_{t}^{*} / u_{t-1}^{*}$, into changes in the total inflow rate, $s_{t}$, and changes in the total outflow rate, $f_{t}$. Therefore, we take first differences and rearrange terms to obtain: ${ }^{7}$

$$
\frac{\Delta u_{t}^{*}}{u_{t-1}^{*}}=\underbrace{\left(1-u_{t}^{*}\right)\left(\frac{\Delta s_{t}}{s_{t-1}}\right)}_{\bar{C}_{t}^{S}} \underbrace{-\left(u_{t}^{*} / u_{t-1}^{*}\right)\left(1-u_{t-1}^{*}\right)\left(\frac{\Delta f_{t}}{f_{t-1}}\right)}_{\bar{C}_{t}^{F}}
$$

where $\bar{C}_{t}^{S}$ and $\bar{C}_{t}^{F}$ represent the contributions of percentage changes in the total inflow rate and the total outflow rate, respectively, to percentage changes in the steady-state

7 Equation (5) is not identical to eq. (8) in Smith (2011) as we do not approximate $u_{t}^{*}$ by $u_{t-1}^{*}$. 
unemployment rate. Furthermore, we are able to decompose $\bar{C}_{t}^{S}$ and $\bar{C}_{t}^{F}$ into changes in the direct and the indirect components (which are defined accordingly):

$$
\begin{aligned}
\frac{\Delta u_{t}^{*}}{u_{t-1}^{*}}= & \overbrace{\frac{\left(1-u_{t}^{*}\right)}{s_{t-1}} \Delta \lambda_{t}^{E U}}^{\bar{C}_{t}^{E U}}+\overbrace{\frac{\left(1-u_{t}^{*}\right)}{s_{t-1}} \Delta\left[\frac{\lambda_{t}^{E I} \lambda_{t}^{I U}}{\left.\lambda_{t}^{I U}+\lambda_{t}^{I E}\right]}\right.}^{\bar{C}_{t}^{E I U}} \\
& \underbrace{-\frac{u_{t}^{*}}{u_{t-1}^{*}} \frac{\left(1-u_{t-1}^{*}\right)}{f_{t-1}} \Delta \lambda_{t}^{U E}}_{\bar{C}_{t}^{U E}}-\underbrace{-\frac{u_{t}^{*}}{u_{t-1}^{*} \frac{\left(1-u_{t-1}^{*}\right)}{f_{t-1}} \Delta\left[\frac{\lambda_{t}^{U I} \lambda_{t}^{I E}}{\lambda_{t}^{I U}+\lambda_{t}^{I E}}\right]}}_{\bar{C}_{t}^{U E}}
\end{aligned}
$$

Following Fujita and Ramey (2009), the relative contribution of margin $X$ to the variability in the steady-state unemployment rate in a given sample period can then be quantified as:

$$
\beta^{*, X}=\frac{\operatorname{Cov}\left(\Delta u_{t}^{*} / u_{t-1}^{*}, \bar{C}_{t}^{X}\right)}{\operatorname{Var}\left(\Delta u_{t}^{*} / u_{t-1}^{*}\right)}
$$

3.1.2 Empirical fit A known weakness of the method described is that it accurately determines the ins and outs of unemployment only if changes in the actual unemployment rate, $u_{t}$, are sufficiently well approximated by changes in the steady-state unemployment rate, $u_{t}^{*}$ (Elsby et al., 2013). The right panel of Fig. 2 illustrates that in the USA, this is indeed the case. Both time series behave remarkably similar at business cycle frequencies as well as in first differences. In particular, we note that the half-life of a deviation from the steady-state unemployment rate is only about one month (see also Elsby et al., 2009). In West Germany, by contrast, the steady-state unemployment rate does not serve as a good approximation, but only as a noisy indicator (see the left panel of Fig. 2 ). ${ }^{8}$ The resulting halflife of a deviation from the steady-state unemployment rate is more than nine months. Even more important, in first differences, the volatility of the steady-state unemployment rate is greater by several orders of magnitude.

The reason for the large approximation error in West Germany is the low level of the underlying labour market transition rates. Intuitively, when labour market transition rates are low, large percentage changes in $s_{t}$ and $f_{t}$ lead to large percentage changes in the associated steady-state unemployment rate, but have only a partial contemporaneous effect on the actual unemployment rate (Elsby et al., 2013, note 27). However, as further argued by these authors, the steady-state decomposition method erroneously attributes the full effect contemporaneously. Therefore, we observe that changes in $s_{t}$ and $f_{t}$ 'explain' more than $156 \%$ of the movements in the actual West German unemployment rate, compared to $102 \%$ in the USA (see Online Appendix Table A.2). Obviously, the steady-state decomposition method is unable to provide reasonable estimates for countries with low labour market transition rates.

8 As documented by Elsby et al. (2013), the USA is a major exception rather than the rule amongst most OECD countries. 

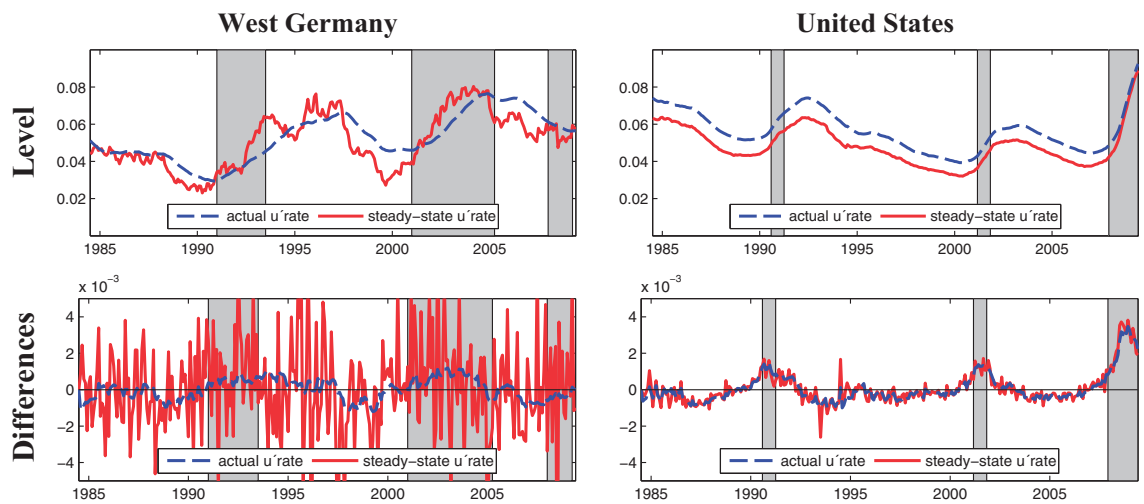

Fig. 2. The actual (dashed line) and the steady-state (solid line) unemployment rate in levels (top panel) and in first differences (bottom panel) for West Germany (left panel) and the USA (right panel), respectively

The grey shaded areas denote recessions dated by the Sachverständigenrat zur Begutachtung der gesamtwirtschaftlichen Entwicklung (2009, p. 260) and the NBER (2010), respectively.

\subsection{Non-steady-state decomposition}

3.2.1 Discretisation To account for the low level of labour market transition rates in West Germany, we study the ins and outs of unemployment using the non-steady-state decomposition method developed by Smith (2011) and Elsby et al. (2013). The starting point of this method is the law of motion of the actual unemployment rate, $u_{t}$ :

$$
\begin{gathered}
\dot{u}_{t}=\left(1-u_{t}\right) s_{t}-f_{t} u_{t} \\
u_{t}=\underbrace{\frac{s_{t}}{s_{t}+f_{t}}}_{u_{t}^{*}}-\frac{\dot{u}_{t}}{s_{t}+f_{t}}
\end{gathered}
$$

where implicitly zero labour force growth is assumed. In other words, workers may flow between all three labour force states, but the change in the number of unemployed workers, $\dot{U}_{t}$, is assumed to equal the negative of the change in the number of employed workers, $-\dot{E}_{t}$, at all times; that is, $\dot{I}=0 .{ }^{9}$ Next, we differentiate eq. (9) with respect to time $t$, discretise, and rearrange terms. This yields the following recursive structure:

$$
\Delta u_{t}=\frac{\Delta u_{t}^{*}}{u_{t-1}^{*}} \underbrace{\frac{s_{t-1}\left(s_{t}+f_{t}\right)}{\left(s_{t}+f_{t}\right)^{2}+\left(s_{t-1}+f_{t-1}\right)}}_{F_{t}}+\Delta u_{t-1} \underbrace{\frac{\left(s_{t}+f_{t}\right)}{\left(s_{t}+f_{t}\right)^{2}+\left(s_{t-1}+f_{t-1}\right)}}_{G_{t}}+\epsilon_{t}
$$

where the residual, $\epsilon_{t}$, captures violations of maintained assumptions; that is, zero labour force growth, constant transition rates within months due to discretisation, or linearity (Smith, 2011). According to eq. (10), the change in the actual unemployment rate, $\Delta u_{t}$, is a

9 In our sample period, labour force growth averages around 0.0005 on a monthly basis (Statistisches Bundesamt, 2012), whilst the sum of the two transition rates, $f_{t}+s_{t}=0.063$, is greater by more than two orders of magnitude (see Table 1). Thus, allowing for labour force growth does not seem quantitatively important (Elsby et al., 2013). 
function of the percentage change in the steady-state unemployment rate, $\Delta u_{t}^{*} / u_{t-1}^{*}$, and the lagged change in the actual unemployment rate, $\Delta u_{t-1}$; with time-varying coefficients, $F_{t}$ and $G_{t}$, respectively.

3.2.2 Empirical fit According to Smith (2011), the mean value of $F_{t} / u_{t-1}^{*}$ can be interpreted as the average monthly rate of convergence; the mean value of $G_{t} \approx 1-F_{t} / u_{t-1}^{*}$ is the corresponding autoregressive coefficient which represents the impact of past changes in the underlying transition rates on the current unemployment rate. If the rate of convergence approaches unity, the non-steady-state decomposition method nests the steady-state approach as a special case. In West Germany, however, the average monthly rate of convergence is as low as $6 \%$. Even in the USA, the average monthly rate of convergence is not larger than $37 \%$. This result illustrates that the non-steady-state decomposition method captures the sluggishness of the West German labour market more appropriately.

The empirical fit of the non-steady-state decomposition method can be tested by comparing the time path of the actual West German unemployment rate, $u_{t}$ (represented by the dashed line in the top left panel of Fig. 3), with the time path of the unemployment rate generated by the right-hand side of eq. (10), $\Delta u_{t}^{R H S}$ (represented by the solid line). We observe that the generated unemployment rate, $\Delta u_{t}^{R H S}$, is about 1 percentage point lower (due to the initial deviation from steady-state), but the cyclical properties are extremely similar. In addition, the bottom left panel of Fig. 3 shows that the theoretical relationship holds remarkably well also in first differences (note the striking difference to Fig. 2). Moreover, in the USA, the two time series are virtually identical—both in levels and in first differences.

3.2.3 Dynamic contributions As explained by Smith (2011), the percentage change of the steady-state unemployment rate in eq. (10), $\Delta u_{t}^{*} / u_{t-1}^{*}$, can be decomposed further into the steady-state contributions of total inflows and total outflows (see eq. 5). We then iterate the resulting expression ad infinitum. Consequently, the dynamic contributions of total inflows and total outflows, respectively, are given as (see Online Appendix Section A.4):

$$
\begin{gathered}
C_{t}^{S}=F_{t} \bar{C}_{t}^{S}+G_{t} C_{t-1}^{S} \\
C_{t}^{F}=-F_{t} \bar{C}_{t}^{F}-G_{t} C_{t-1}^{F}
\end{gathered}
$$

where, by assumption, $C_{0}^{S}=C_{0}^{F}=\Delta u_{0} / 2$. Figure 4 depicts the time paths of the dynamic contributions (solid line) and the first differences of the actual unemployment rate (dashed line) for both countries. The graphs confirm the impression drawn from Fig. 1. In West Germany, the co-movement between $\Delta u_{t}$ and $C_{t}^{S}$ seems closer than with $C_{t}^{F}$, whereas in the USA the reverse situation prevails. In addition, analogously to eq. (6), we are able to decompose both $C_{t}^{S}$ and $C_{t}^{F}$ into changes in the direct and the indirect components, that is, $C_{t}^{E U}, C_{t}^{E I U}, C_{t}^{U E}$, and $C_{t}^{U I E}$ (not shown here). ${ }^{10}$

Finally, we quantify the relative contribution of margin $X$ to the variability in the actual unemployment rate in two stages. First, we compute the $\beta$ values between the change in

10 We impose the following initial guess: $C_{0}^{E U}=C_{0}^{U E}=0.4 \Delta u_{0}, C_{0}^{E I U}=C_{0}^{U I E}=0.1 \Delta u_{0}$. 

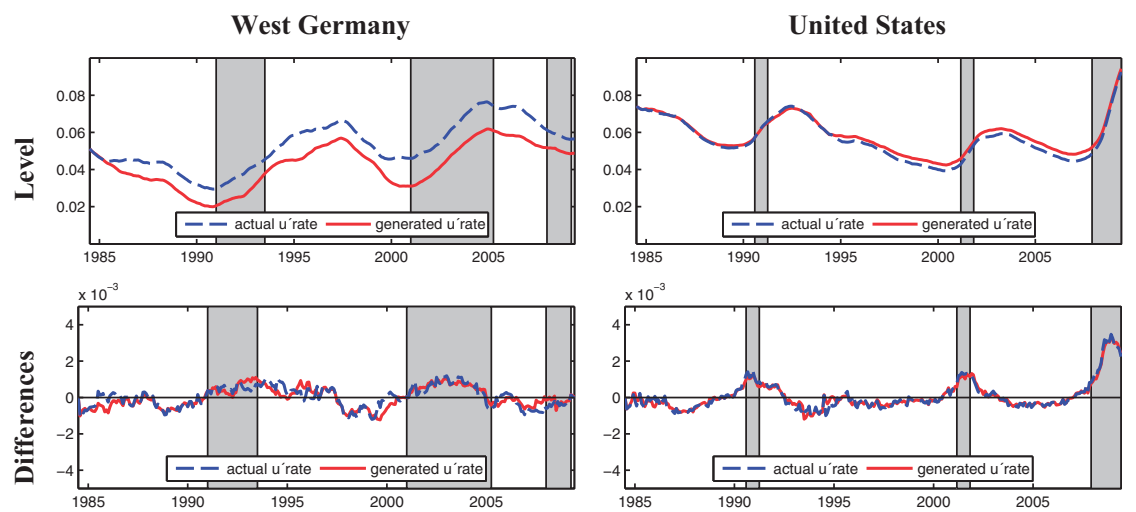

Fig. 3. The actual (dashed line) and the model generated (solid line) unemployment rate in levels (top panel) and in first differences (bottom panel) for West Germany (left panel) and the USA (right panel), respectively

The grey shaded areas denote recessions dated by the Sachverständigenrat zur Begutachtung der gesamtwirtschaftlichen Entwicklung (2009, p. 260) and the NBER (2010), respectively.
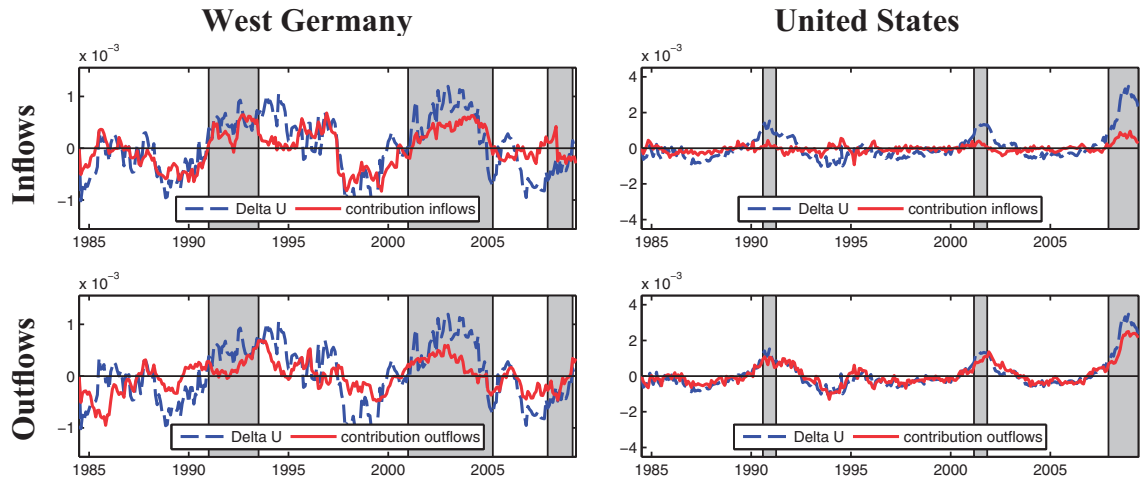

Fig. 4. The contributions of the total inflow rate (solid line, top panel) and the total outflow rate (solid line, bottom panel) to changes in the model generated unemployment rate (dashed line) for West Germany (left panel) and the USA (right panel), respectively

The grey shaded areas denote recessions dated by the Sachverständigenrat zur Begutachtung der gesamtwirtschaftlichen Entwicklung (2009, p. 260) and the NBER (2010), respectively.

the actual unemployment rate, $u_{t}$, on the one hand, and the change in the unemployment rate generated by the right-hand side of eq. (10), $\Delta u_{t}^{R H S}$, and the residual, $\epsilon_{t}$, on the other hand: ${ }^{11}$

$$
\beta^{U}=\frac{\operatorname{Cov}\left(\Delta u_{t}, \Delta u_{t}^{R H S}\right)}{\operatorname{Var}\left(\Delta u_{t}\right)}, \quad \beta^{\epsilon}=\frac{\operatorname{Cov}\left(\Delta u_{t}, \epsilon_{t}\right)}{\operatorname{Var}\left(\Delta u_{t}\right)}
$$

11 The advantage of our two-stage procedure is that by construction, the relative contributions of the total inflow rate and the total outflow rate add up to 1 . 
Second, we compute the average contribution of margin $X$ to changes in $\Delta u_{t}^{R H S}$ :

$$
\beta^{X}=\frac{\operatorname{Cov}\left(\Delta u_{t}^{R H S}, C_{t}^{X}\right)}{\operatorname{Var}\left(\Delta u_{t}^{R H S}\right)}
$$

where, to capture deviations from the steady-state in the initial period (see the bottom left panel of Fig. 3), the first 18 data points (1984M7-1985M12) are discarded.

\section{The ins and outs of unemployment}

Table 3 shows the decomposition results for West Germany and the USA. The estimates in the first row, $\beta^{U}$, measure the overall model fit (see eq. 13). ${ }^{12}$ In the full sample representative of the entire population of West Germany, the dynamic decomposition accounts for $83 \%$ of all changes in the actual unemployment rate, $\Delta u_{t}$. Put differently, $17 \%$ of all changes in the actual unemployment rate remain unexplained. Several observations indicate that the discrepancy is very likely due to sampling error. ${ }^{13}$

\subsection{West Germany}

Table 3, Panel A displays the decomposition results for all West German sub-samples. We observe that in the full sample, changes in the total inflow rate account for $60 \%$ of the changes in $u_{t}^{R H S}$ (see eq. 13 ), and only $40 \%$ are due to changes in the total outflow rate. Most of the variability, about $80 \%$, is due to direct transitions between employment and unemployment, whilst $20 \%$ of the variability is due to indirect transitions through inactivity (particularly by women and foreigners). Moreover, we find that the dominance of inflows over outflows is very robust across all demographic sub-samples but the young (where the outflow margin is more important, but the difference is not significant at the $10 \%$ level). More generally, we note that in both countries, the relative importance of the inflow margin rises over the life cycle. This pattern suggests that the business cycle is an important determinant of labour market entry (for the young) and exit (for the old). Interestingly, the young account for almost all the variability in transitions to employment via inactivity (e.g., schooling) in the West German sub-sample, whereas the old contribute above the average to the variability in direct transitions from employment to unemployment. The latter observation indicates the presence of cyclical (hidden) early retirement (see also Bachmann, 2005).

12 See Section A.5 in the Online Appendix for the decomposition results when all frequencies higher than eight years are filtered out prior to estimation.

13 Note, therefore, that the fit of the full sample $(9,044$ observations on average) is superior to the fit of the German sample $(81 \%$, with 7,577 observations on average), even though the fit of the foreigner sample $(61 \%$, with 1,467 observations on average) is clearly worse. In the USA, on the other hand, where the average number of observations is larger by a factor of eight, we observe that the model fit is much better ( $94 \%$ for the full sample). Moreover, consistent with the sampling error hypothesis, we also note that the model fit of small US subsamples (e.g., the young or the old) is somewhat lower (about $89 \%$ ). The sampling error hypothesis is also confirmed by the near unity (0.92) correlation coefficient between the log number of observations and the estimated model fit across all subsamples. 


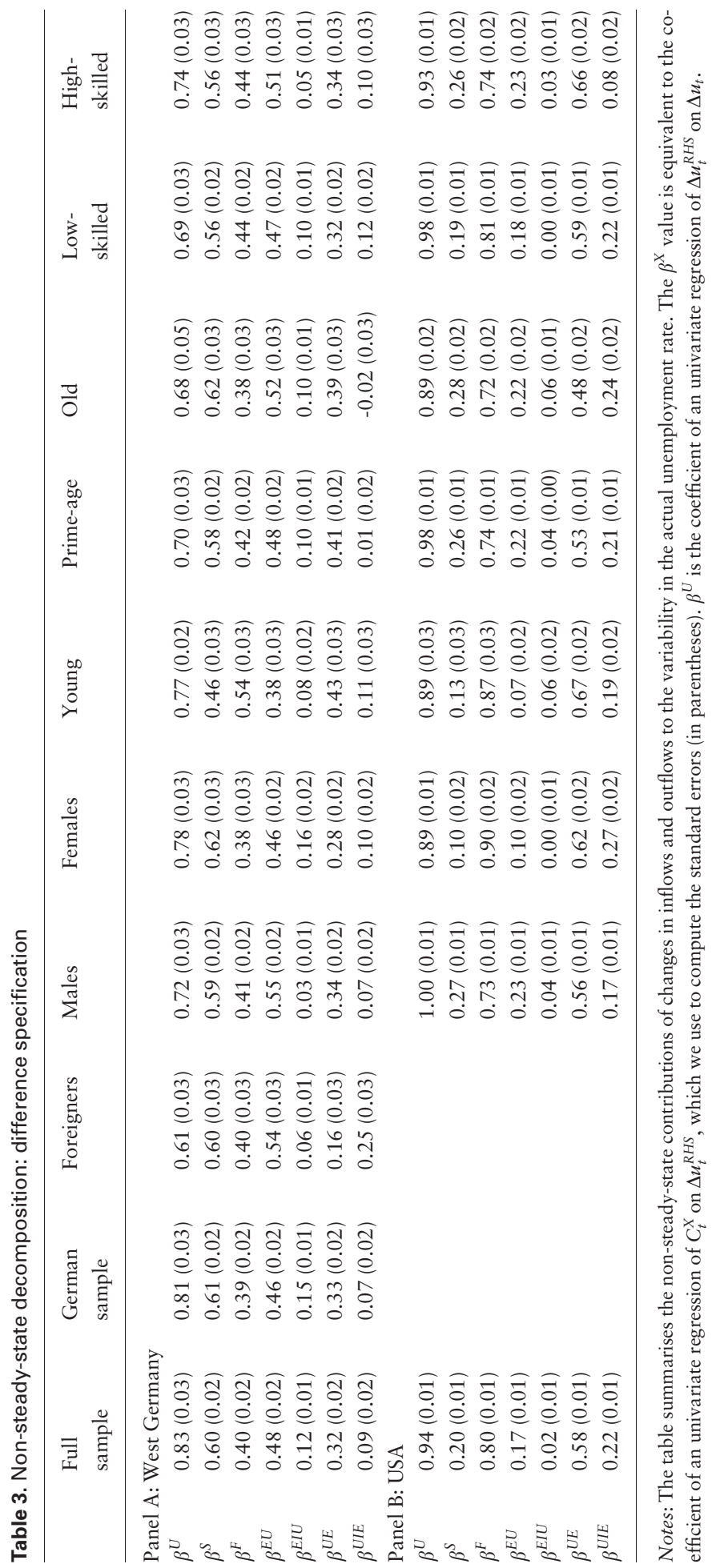




\subsection{USA}

Table 3, Panel B illustrates the decomposition results for all US sub-samples. In stark contrast to West Germany, only $20 \%$ of all changes in $u_{t}^{R H S}$ (see eq. 13 ) are due to changes in the total inflow rate, whilst $80 \%$ are due to changes in the total outflow rate. The relative importance of direct $(75 \%)$ versus indirect $(25 \%)$ transitions, on the other hand, is similar to the West German sample. The dominance of outflows over inflows is robust across all sub-samples. As already mentioned, the relative importance of the inflow margin increases over the life cycle. Moreover, in the male sub-sample, inflows seem somewhat more important than in the female sub-sample. Transitions involving inactivity are particularly important for women and the old.

\section{Discussion}

In recent years, the steady-state decomposition method has attracted a great deal of attention, with a particular focus on the USA (Elsby et al., 2009; Fujita and Ramey, 2009; Shimer, 2012). ${ }^{14}$ The non-steady-state approach has been applied to UK data by Smith (2011) and to French data by Hairault et al. (2012). Overall, there seems to be a consensus that the outflow rate is more important than the inflow rate in all Anglo-Saxon countries except Ireland, whereas in most European countries both transition rates are roughly equally important. This conclusion stems from a non-steady-state decomposition of unemployment duration data (Elsby et al., 2013) — the earliest attempt to examine the ins and outs of German unemployment as a part of an OECD cross-country study. If available, however, evidence based on panel data (e.g., household survey or processed-induced administrative data) is generally preferred because panel data provide a direct measurement of the underlying gross worker flows (Fujita and Ramey, 2009).

Both previous studies that have investigated the ins and outs of German unemployment (Jung and Kuhn, 2014; Nordmeier, 2014) are based on gross worker flows from the IAB employment panel. These data are very accurate, but not representative for the entire population of Germany. In particular, IAB data cover only social security employment and those unemployed who receive benefits (Bachmann and Schaffner, 2009). All other individuals, that is, civil servants, self-employed persons (who together make up about $15 \%$ of the labour force, see Bundesagentur für Arbeit, 2012), the unemployed not entitled to benefits (about a third of all unemployed, see Bachmann, 2005), and inactive individuals out of the labour force are observationally equivalent (information gap). This makes IAB data prone to be confounded with spurious transitions into/out of inactivity.

Nordmeier (2014) addresses this issue by using the non-employment proxy developed by Fitzenberger and Wilke (2010). Accordingly, all information gaps of up to one year are classified as unemployment, provided that the individual has received unemployment benefits either before and/or after an information gap. The non-employment proxy averages about $16 \%$ in her sample (covering East and West Germany). Based on a non-steady-state decomposition, Nordmeier (2014) argues that the outflow (inflow) rate accounts for $40 \%$ $(20 \%)$ of the variation in the non-employment proxy (the residual $40 \%$ remain unexplained). As SOEP data capture inactivity (non-participation) explicitly, we are also able to

14 Adaptations of this methodology to European economies include Petrongolo and Pissarides (2008) for the UK, France, and Spain; Gomes (2011) for the UK, using a longer sample period; and Şengül (2012) for Turkey. 
decompose changes in the West German non-employment rate. ${ }^{15}$ Interestingly, our results are quantitatively very similar to hers (outflows: $39 \%$, inflows: $16 \%$ ). We can thus reconcile the apparently contradictory results.

Alternatively, Jung and Kuhn (2014) treat all information gaps between labour market entry and retirement as inactivity. Consequently, their estimated contribution of indirect transitions involving inactivity is $34 \%$, compared to only $21 \%$ in our sample. Yet consistent with our results, they find that the total inflow rate (about 61\%) in West Germany is more important than the total outflow rate. ${ }^{16}$ The similarity to our results is reassuring but by no means self-evident (given the reasons discussed in Section 3.1.2). In particular, Tables 3 and A.2 (Online Appendix) show that the steady-state decomposition predicts the same dominating margin as the non-steady-state decomposition method in only six out of nine West German sub-samples. Likewise, Elsby et al. (2013, Table 3) report that the estimates for Germany, Ireland, and Italy differ substantially depending on the decomposition method used. ${ }^{17}$ This implies that the application of the steady-state decomposition method to countries with low labour market transition rates is not innocuous (even though the results of Jung and Kuhn, 2014, are not affected by this caveat). Besides that, a comparison of Tables 1 and 2 in this article with Table 1 in Jung and Kuhn (2014) shows that in our sample, both (i) the size difference between mean transition rates in West Germany versus the USA and (ii) the volatility difference of the inflow rate in West Germany versus the USA are substantially greater. Following the argument of Jung and Kuhn (2014), this implies that the gap between matching efficiency in West Germany versus the USA may be even larger.

\section{Conclusion}

This article decomposes fluctuations in the German unemployment rate into changes in inflows (job separation) and outflows (job finding). For this purpose, we construct gross worker flows from the West German sample of the SOEP and the CPS for the USA. Our final sample consists of monthly labour market transition rates from both countries for the period 1984M7-2009M6.

We estimate the ins and outs of West German unemployment using the non-steady-state decomposition method proposed by Smith (2011). This method explicitly takes account of the low level of labour market transition rates in Germany. Our main result is that close to $60 \%$ of changes in the actual unemployment rate are due to changes in the unemployment inflow rate-compared to only $20 \%$ in the United States. In particular, we find that our results are robust across all demographic sub-groups but the young.

The aggregate labour market transition rates constructed in this article are likely to be useful in many future research projects. For instance, in an ongoing research project (Hertweck and Sigrist, 2012), we examine whether the Hartz I-IV reforms have improved

15 Note that the West German non-employment rate averages about $27 \%$ in our SOEP sample.

16 However, in their sample, the pattern is mainly driven by males and medium-skilled workers (see Table 1 in the corresponding working paper, Jung and Kuhn, 2011), whereas our results are robust across all demographic sub-groups but the young.

17 To be precise, Elsby et al. (2013) decompose the actual unemployment rate into changes in inflows and outflows, whereas Jung and Kuhn (2014) decompose changes in the steady-state unemployment rate. 
the efficiency of the matching process in Germany. Moreover, as soon as more recent data are available, it would be interesting to evaluate the behaviour of the German labour market during the Great Recession.

\section{Supplementary material}

Supplementary material is available online at the OUP website.

\section{Acknowledgements}

This article is based on chapter 1 of Sigrist's doctoral dissertation written at the University of Basel and the corresponding working paper 'The Aggregate Effects of the Hartz Reforms in Germany'. Sigrist is indebted to Aleksander Berentsen for his help and supervision. Without implication, both authors thank Ronald Bachmann, Rüdiger Bachmann, Almut Balleer, Regis Barnichon, Carlos Carillo-Tudela, Shigeru Fujita, Pietro Garibaldi, Pedro Maia Gomes, Sebastian Giesen, Matthias Gubler, Philip Jung, Leo Kaas, Michael U. Krause, Steffen Künn, Christian Merkl, Daniela Nordmeier, Jennifer C. Smith, Tijs van Rens, Enzo Weber, Michael Weber, Maximilian Wellschmied, Klaus F. Zimmermann, and two anonymous referees, as well as conference participants at SMYE Aarhus, DIW Berlin, SOEP Berlin, IZA/SOLE Buch am Ammersee, VfS Düsseldorf, ifo Dresden, RWI Essen, ECB/CEPR Frankfurt, EEA Gothenburg, IWH-CIREQ Halle, EA Loccum, RES London, IAB/FAU Nuremberg, EALE Turin, MMM UrbanaChampaign, CEF Vancouver, and brown bag audiences at Penn and Warwick for extensive comments and suggestions. Hermione Miller-Moser, Heike Knappe, and SNB English Language Services provided excellent editorial assistance. Part of this research project was conducted when Hertweck was affiliated with the University of Basel and visiting the University of Pennsylvania, whose hospitality is gratefully acknowledged. Other parts of this research project were completed whilst Hertweck was affiliated with RWTH Aachen University. The views expressed in this article are those of the authors and do not necessarily reflect the view of the Swiss National Bank.

\section{Funding}

Swiss National Science Foundation (118306 to MSH); WWZ Forum (B-115 to OS).

\section{References}

Abowd, J.M. and Zellner, A. (1985) Estimating gross labor-force flows, Journal of Business and Economic Statistics, 3, 254-83.

Bachmann, R. (2005) Labor market dynamics in Germany: hirings, separations, and job-to-job transitions over the business cycle, SFB 649 Discussion Papers No. 2005-045, Humboldt University, Berlin.

Bachmann, R. and Schaffner, S. (2009) Biases in the measurement of labour market dynamics, Tech. Rep. No. 12/2009, SFB 475, Technische Universität Dortmund.

Biewen, M. and Wilke, R. (2005) Unemployment duration and the length of entitlement periods for unemployment benefits: do the IAB employment subsample and the German SocioEconomic Panel yield the same results?, AStA Advances in Statistical Analysis, 89, 209-36.

Bundesagentur für Arbeit (2012) Bezugsgrößen zur Berechnung der Arbeitslosenquoten, Zeitreihe, Statistik Datenzentrum, Nuremberg.

Burda, M.C. and Hunt, J. (2011) What explains the German labor market miracle in the Great Recession?, Brookings Papers on Economic Activity, 42, 273-335. 
CPS (2012) Current Population Survey—a joint effort between the Bureau of Labor Statistics and the Census Bureau, documentation available at http://www.census.gov/cps/ (accessed 9 January 2015); data available at http://www.nber.org/data/cps_basic.html (accessed 9 January 2015).

Darby, M.R., Haltiwanger, J.C., and Plant, M.W. (1986) The ins and outs of unemployment: the ins win, NBER Working Paper No. 1997, Cambridge, MA.

Davis, S.J. (2006) Comments on 'Job loss, job finding, and unemployment in the U.S. economy over the past fifty years' by Robert E. Hall, in M. Gertler and K. Rogoff (eds) NBER Macroeconmics Annual 2005, vol. 20, MIT Press, Cambridge, MA.

Elsby, M., Hobijn, B., and Şahin, A. (2013) Unemployment dynamics in the OECD, Review of Economics and Statistics, 95, 530-48.

Elsby, M.W.L., Michaels, R., and Solon, G. (2009) The ins and outs of cyclical unemployment, American Economic Journal: Macroeconomics, 1, 84-110.

Fitzenberger, B. and Wilke, R. (2010) Unemployment durations in West-Germany before and after the reform of the unemployment compensation system during the 1980s, German Economic Review, 11, 336-66.

Fujita, S. (2011) Dynamics of worker flows and vacancies: evidence from the sign restriction approach, Journal of Applied Econometrics, 26, 89-121.

Fujita, S., Nekarda, C.J., and Ramey, G. (2007) The cyclicality of worker flows: new evidence from the SIPP, Working Paper No. 07-5, Federal Reserve Bank of Philadelphia, PA.

Fujita, S. and Ramey, G. (2009) The cyclicality of separation and job finding rates, International Economic Review, 50, 415-30.

Gartner, H., Merkl, C., and Rothe, T. (2012) Sclerosis and large volatilities: two sides of the same coin, Economics Letters, 117, 106-9.

Gomes, P. M. (2011) Labour market flows: facts from the United Kingdom, Labour Economics, $19,165-75$.

Haile, G.A. (2009) The nature and extent of job separations in Germany: some new evidence from SOEP, SOEP Papers on Multidisciplinary Panel Data Research No. 208, Deutsches Institut für Wirtschaftsforschung, Berlin.

Hairault, J.-O., Le Barbanchon, T., and Sopraseuth, T. (2012) The cyclicality of the separation and job finding rates in France, IZA Discussion Paper No. 6906, Institute for the Study of Labor, Bonn.

Hall, R.E. (2006) Job loss, job finding, and unemployment in the U.S. economy over the past fifty years, in M. Gertler and K. Rogoff (eds) NBER Macroeconomics Annual 2005, vol. 20, MIT Press, Cambridge, MA.

Hertweck, M.S. and Sigrist, O. (2012) The aggregate effects of the Hartz reforms in Germany, Working Paper Series of the Department of Economics No. 2012-38, University of Konstanz.

Hodrick, R.J. and Prescott, E.C. (1997) Postwar U.S. business cycles: an empirical investigation, Journal of Money, Credit and Banking, 29, 1-16.

Jung, P. and Kuhn, M. (2011) The era of the U.S.-Europe labor market divide: what can we learn?, MPRA Paper No. 32322, University Library of Munich.

Jung, P. and Kuhn, M. (2014) Labor market institutions and worker flows: comparing Germany and the U.S., Economic Journal, 124, 1317-42.

Jürges, H. (2007) Unemployment, life satisfaction and retrospective error, Journal of the Royal Statistical Society Series A, 170, 43-61.

Kraus, F. and Steiner, V. (1998) Modelling heaping effects in unemployment duration modelswith an application to retrospective event data in the German Socio-Economic Panel, Jahrbücher für Nationalökonomie und Statistik, 217, 550-73.

Kroh, M. (2011) Documentation of sample sizes and panel attrition in the German SocioEconomic Panel (SOEP) 1984-2010, Data Documentation No. 59, Deutsches Institut für Wirtschaftsforschung, Berlin. 
Möller, J. (2010) The German labor market response in the world recession: de-mystifying a miracle, Zeitschrift für Arbeitsmarkt Forschung, 42, 325-36.

NBER (2010) US business cycle expansions and contractions, National Bureau of Economic Research, Cambridge, MA; available at http://www.nber.org/cycles/cyclesmain.html (accessed 9 January 2015).

Nordmeier, D. (2014) Worker flows in Germany: inspecting the time aggregation bias, Labour Economics, 28, 70-83.

Petrongolo, B. and Pissarides, C. A. (2008) The ins and outs of European unemployment, American Economic Review, 98, 256-62.

Sachverständigenrat zur Begutachtung der gesamtwirtschaftlichen Entwicklung (2009) Die Zukunft nicht aufs Spiel setzen, Jahresgutachten 2009/10, Statistisches Bundesamt, Wiesbaden.

Sala, L., Söderstrom, U. and Trigari, A. (2013) Structural and cyclical forces in the labor market during the Great Recession: cross-country evidence, NBER International Seminar on Macroeconomics 2012, 9, 345-404.

Schmidt, C.M. (2000) Persistence and the German unemployment problem: empirical evidences on German labor market flows, Economie et Statistique, 2/3, 83-95.

Şengül, G. (2012) The ins and outs of unemployment in Turkey, Working Paper No. 12/10, Central Bank of the Republic of Turkey, Ankara.

Shimer, R. (2012) Reassessing the ins and outs of unemployment, Review of Economic Dynamics, 15, 127-48; data and computer codes available at https://sites.google.com/site/robertshimer/ research/flows (accessed 22 January 2015).

Smith, J.C. (2011) The ins and outs of UK unemployment, Economic Journal, 121, 402-44.

SOEP (2011) Socio-Economic Panel (SOEP), data for years 1984-2010, version 27.0.

Statistisches Bundesamt (2012) Bevölkerung nach Beteiligung am Erwerbsleben, Ergebnisse des Mikrozensus 1957-2011, Wiesbaden.

The Economist (1999) The sick man of the Euro; available at http://www.economist.com/node/ 209559 (accessed 8 January 2015).

Wolff, J. (1998) Selected topics in unemployment duration in two economies in transition: East Germany and Hungary, Ph.D. Thesis, European University Institute, Florence.

Wolff, J. and Augustin, T. (2003) Heaping and its consequences for duration analysis: a simulation study, Allgemeines Statistisches Archiv, 87, 59-86.

Yashiv, E. (2008) U.S. labor market dynamics revisited, Scandinavian Journal of Economics, 109, 779-806. 